\title{
ON SECOND CHANCES, EPISTEMOLOGICAL SHIFTS AND BECOMING HYDRA
}

\author{
Oonagh McGirr
}

\section{INTRODUCTION}

This paper outlines the impact of a personal decision to make a geographical shift on my field of study and framework of practice. A benign career move in 2017 directly affected the professional doctoral study (Ed.D) I had been conducting while employed in the Middle East. This bumpy career moment required an agile response to a wicked professional problem (Head, 20I5). This article focuses on the challenge we, as researchers, often seek to mitigate and truly hope never to encounter - the withdrawal of ethical approval to complete a study in a specific place or space. In recounting the multiple problems faced, I address the solutions-focused approach, the discussions held and resolution of the problem of the apparent loss of time, effort and funds invested over a period of four years. I share philosophical shifts in thinking and practice which emerged during a period of recasting of the framework and planning for the Doctor of Professional Practice (DPP). I detail a repositioning rooted in reflexivity, drawing on the experiential and reflective nature of lived experience of professional practice. I identify the key learnings and provide an overview of the original study contrasted with the paradigmatically evolved positionality for the reworked study. In brief, how not to lose it when you think you are losing it, doctorally speaking.

At the time of writing, I observe that the moment of paradoxically certain unpredictability we are living is particularly meaningul in terms of my personal and professional narrative. In the midst of a global pandemic and looming economic recession, our futures seem subject to stress, volatility and continuous recalibration. My journey of doctoral practice is illustrative of the bumpy moment roadblock (Romano, 2006), bestowing an opportunity for development and growth. Here I present an exploration and summary of the change effected by a specific jarring moment in my personal study trajectory.

\section{FROM HERE TO THERE}

As I tapped the phone screen to end the call, a feeling of palpable dread began to rise steadily. Stuck in more ways than one, the realisation hit me - four years of work had just been abruptly closed down with the words, "We are kindly informing you that you are no longer permitted to conduct research here." So ended the possibility and probability of being able to close out on the final stage of data analysis and re-presentation for the doctoral research project I had begun in 2012. This, for sure, was the most critical of incidents (Tripp, 1993, 2012) in my professional life to date.

In 20 I2, after completing a Master's degree in Higher Education practice, I embarked upon the next logical step - a professional doctorate, the focus of which was to be an exploration of practice and identity of higher educators in the Middle East. The choice of locus for the research project was informed by my physical location and site of professional practice; I was employed at a higher education institution in the Arabian Gulf, leading learning and teaching development activity for a centre of vocational education and training (VET). 
Working alongside fellow educators to upskill and share opportunities for enhancement of practice, I had become increasingly curious about the benchmark concept of 'good practice' (for teaching and learning). The ubiquitous usage of the term, which peppers our discussions, provides food for research thought, (apparently) informs our teaching endeavours, and appeared to hold different meanings for the different academic 'tribes' (Becher \& Trowler, $200 \mathrm{I}$ ) I encountered. Understanding that context is often critical to our research, I was keen to discover if the local ethno-religious cultural mores (Rieder, 2018) informed the practice of the multinational group of colleagueeducators I was associating with. I wondered, too, if the dominant religious practice of the Arab-nation location influenced the practitioners' perceptions and experience of good (teaching) practice.

As I scoped the research project, it became clear to me that the focus of investigation would be two-fold - getting to the essence of the concept and uncovering what this meant for the educators in terms of daily practice. In summary, I decided upon a phenomenological study (van Manen, 1997) of the identity in practice of fellow teachers, conducted through a series of group and individual interviews and to be recounted, ultimately, as a series of short narrated vignettes of practice. The purpose of this co-constructed endeavour was to document then current accounts of educators' professional practice. By invoking the constructivist, I would voice these shared stories of identity in practice. An underpinning aim of the project, as outlined in the original proposal, was "to make the voices of those teachers audible ... to represent them in some way through their stories of ... the ordinary and the extraordinary, the quotidian and the exotic, the routine and the surprising, the dull and the ecstatic" (McGirr, 2019a).

\section{Hoops and Hurdles}

By 201 6, key milestones had been met and much progress made. The data generated from the research conversations had been collected, collated and analysed. The last stage entailed presenting draft narratives to the participants for feedback, to inform the subsequent honing of these voiced practitioner stories for the final thesis.

\section{No is for 'Nomad'}

Three days before Christmas in 2016, I received a formal offer of employment on the other side of the world - in Aotearoa-New Zealand. I had worked carefully throughout the six-month employment recruitment process to progress as much of the doctorate as I could. I was keen to ensure that, in the unlikely event (or so it seemed at the time of writing the proposal 18 months earlier) that I was to change employment (and the locus of the study); all data would be safely and securely collected and stored. By the time the offer was made, the initial write-up of the study was in train. As I left the Middle Eastern summer for the southern hemisphere winter, I felt confident that the remaining milestones were achievable and submission of the final artefact would occur, by 2018 as planned.

\section{The 'Sucker Punch'}

Once relocated, I worked to identify a time to meet the participants (virtually) and share the draft vignettes I had begun to construct. The intention was to provide an opportunity to review and share feedback on the drafts I had created - with a particular focus on the authenticity of the fictional personae - to ascertain if I had been able to highlight aspects of meaning and identity within the community of those researched. The feedback provided by the educators would also indicate whether I had been able to protect their identity (a key ethical consideration, given the political context in which the study had been conducted).

By mid-20 I7, after a series of seemingly ordinary exchanges about unresolved contractual matters, I received a parallel communication about my research project. In effect, with a change of leadership and governance at my former place of employment, a directive was issued to suspend any research projects involving staff of the entity; and the rationale was simple - recalibration of focus and expectations. There was no commentary or reference to the research per se, nor to the findings generated (these had only been shared confidentially with the participants at the 
very early stages of analysis). The rationale for the suspension of permission to conduct research was communicated as linked to a change in institutional policy. It was intimated that updates regarding the work should have been shared with the senior administrators of the college (although this was not explicitly stated, nor previously required). Ironically, the findings and emerging narratives in my study spoke of the institution in glowing terms - as a site of caring and creativity in which learners were able to grow their skills and knowledge precisely because of the college's expectation of holistic support for the student body.

The sucker punch (McGirr, 2019a, p. 14) had been landed suddenly, squarely and firmly.

\section{The 'Black Swan' of Covid-19}

The irruption of Covid-19 in early 2020 may be the pan-global Black Swan (Taleb, 2007) of our decade. Like its predecessors, it has placed into sharp relief a confluence of contexts - personal, professional and geopolitical. The combination of a disruptive sector reform (ROVE),' the unrelenting global pandemic (Covid-19) and a need to recalibrate professional attention have provided me with an opportunity to reflect on how all of these factors affect my exploration of professional practice.

The combined challenge of the Reform of Vocational Education and Covid-19 - 'ROV(E)ID-19'2 - highlights the interconnected nature of the narrow intrinsic and broader extrinsic forces at play in the professional milieu. This inseparability of the past and present, the professional and personal, is evidenced by the need to recast the work, reflecting on a range of phenomena which inform the here and now of my practice, so crucial to the identification of a worthwhile research project.

\section{Problem-solving}

In pondering a solution to my doctoral dilemma, I had imagined initially that I might join the Doctor of Professional Practice (DPP) at Otago Polytechnic in the latter stages, effectively transferring the project over from one institution to another, based on an approximate recognition of the phase and stage of progress. However, as discussions unfolded with my academic mentors and reporting line manager, it became evident that there was more value in taking all I had already explored and recasting the study - the more so, given the differences in context and programme.

\section{Case Study and self}

The benefit of this (renewed) approach lies in undertaking a project which is meaningful to my current role, and which speaks to the "retrospective and prospective benefits of my work and practice" (Lester, 2004, p. 76I). By drawing on past and present experiences to inform a framework for future professional practice, I am able to engage with a documented process of self-managed development. Recommencement acknowledges that the previous work also informs the undertaking which is the DPP. Completing a comprehensive review of learning, compiling notes and continuous commentary in a reflective journal have proved to be valuable in terms of activating schemata and fully recognising the epistemological shift experienced in the intervening period.

\section{Professional Shifts and Changes in Practice}

The change of project focus echoes the change of role and professional context. This has involved moving from an operational management role as a tier-four leader, working with fellow academic teaching and development practitioners and leading a single portfolio unit, to my current role as a tier-two leader, responsible for a portfolio of seven discrete directorates whose focus is on work-based, practically engaged capability-building for tertiary education. The evolving nature of role and practice underlines the inherent complexity of professional practice; positions are here today and gone tomorrow, reinforcing the need to consider carefully the focus and value of the project. 


\section{Recalibration}

Recalibrating the direction of study (Figure 2) entailed reflection on past and current contexts and facilitated a certain criticality through robust dialogue with academic mentors and peers. By conducting a realistic critique of the relevance of transferring the study, I saw the need to reconfigure the research project. Reflecting critically, I identified the need to take back the power by finding a way to continue with my professional development. I responded to an act of powerful sabotage and loss of crucial ethical approval through collaborative problem-solving; I was able to exert more control over my (study) life at that particular point in time.

Simply put, the initial project had become outdated (literally); out of scope of my current practice (strategic leadership); questionable in terms of its currency (others have conducted and completed studies in the interim period); irrelevant to my current context (a different geographical and political context); and practicably unfeasible (no approval to continue the research project). In true autoethnographic tradition (Ellis, Adam, \& Bochner, 20 I 0), my considered pivot embodies the necessary change effected in response to power shifts in the professional domain.

The need for substantial change emerged as I worked through the Review of Learning (McGirr, 2019a) for the DPP.The word cloud (Figure I) and table (Figure 2) identify and summarise the epistemic differences between the original and current research projects. Both are outputs I created as I updated my reflective blog and conducted an analysis of the similarities and differences identified when comparing the original doctoral project and the emerging (new) project, on which I have settled.

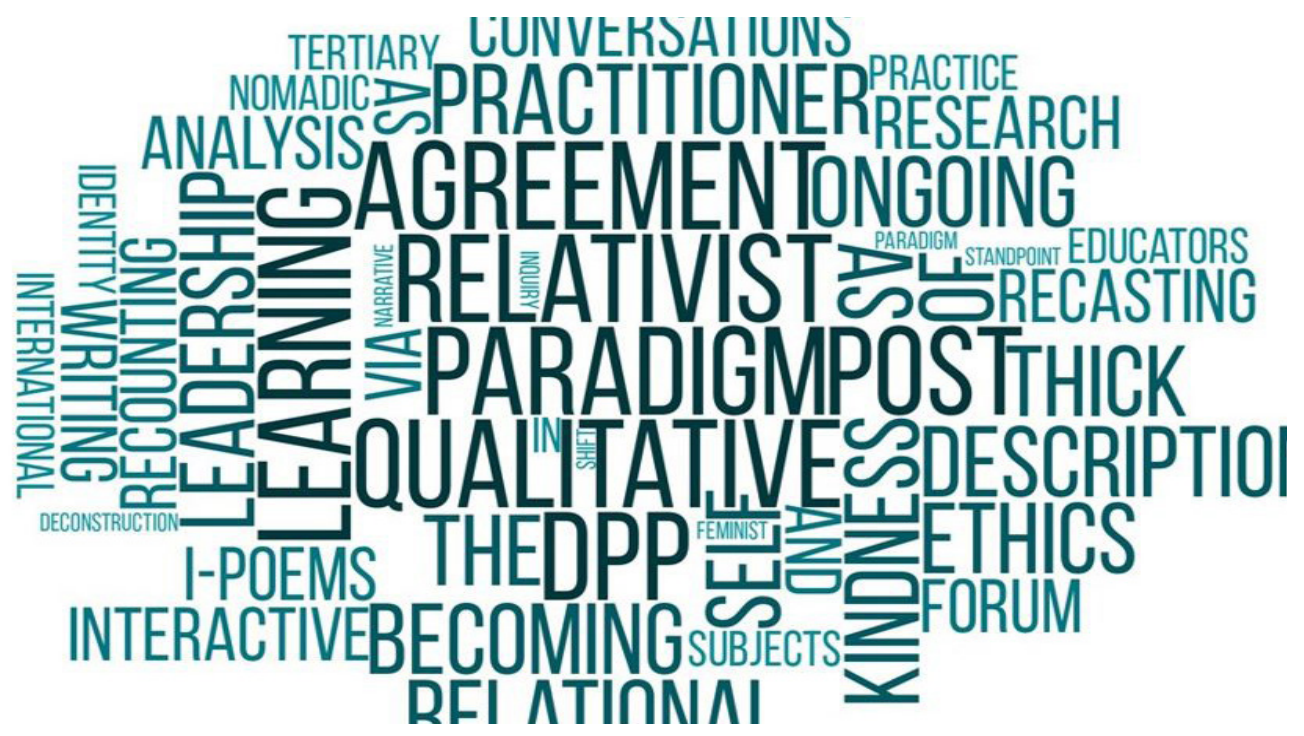

Figure 1. Word cloud for professional practice project

\section{Writing the self and culture}

The key difference in the previous and current doctoral project is the methodological approach of autoethnography. It strikes me that such a method permits a wider scope of exploration by invoking the personal in professional practice. While I continue to honour the qualitative nature of the original project, an autoethnographic approach allows me to "connect the autobiographical and personal to the cultural, social and political" (Ellis, 2004, p. xix), which in turn speaks to the storied nature of the professional practice endeavour. 


\begin{tabular}{|c|c|c|c|}
\hline Paradigm & Ontology/epistemology & Professional practice context & Research focus \\
\hline \multicolumn{4}{|c|}{ Proposal for Doctorate of Education Research Project } \\
\hline Qualitative & $\begin{array}{l}\text { Constructivist } \\
\text { Narrative inquiry } \\
\text { Interpretative lens } \\
\text { Fictional narrative } \\
\text { Assumptions about } \\
\text { knowledge, self and } \\
\text { power } \\
\text { Theories of agency and } \\
\text { construction of identity }\end{array}$ & $\begin{array}{l}\text { Tier four leader at a Middle } \\
\text { Eastern HEI } \\
\text { Operational lead for single } \\
\text { directorate } \\
\text { Intereest in teacher identity } \\
\text { in practice, professional } \\
\text { development frameworks } \\
\text { and versions of teacher self }\end{array}$ & $\begin{array}{l}\text { Exploration of the } \\
\text { practice and } \\
\text { philosophies of teachers } \\
\text { on undergraduate } \\
\text { programmes at a higher } \\
\text { education institution } \\
\text { Presented as a narrated } \\
\text { commentary of the } \\
\text { multiple identities } \\
\text { encountered }\end{array}$ \\
\hline \multicolumn{4}{|c|}{ Proposal for Doctor of Professional Practice Research Project } \\
\hline $\begin{array}{l}\text { Post } \\
\text { qualitative }\end{array}$ & $\begin{array}{l}\text { Post structural } \\
\text { Relativist } \\
\text { Subjectivist } \\
\text { Feminist standpoint } \\
\text { Narrative inquiry } \\
\text { Assumptions about } \\
\text { leadership } \\
\text { Theories of agency, } \\
\text { discourse and } \\
\text { construction of identity }\end{array}$ & $\begin{array}{l}\text { Tier two leader } \\
\text { Strategic lead for six } \\
\text { operational directorates } \\
\text { Interest in academic } \\
\text { leadership, women in } \\
\text { leadership, identity in } \\
\text { practice }\end{array}$ & $\begin{array}{l}\text { Exploration of the } \\
\text { practice of strategic } \\
\text { leadership at a time of } \\
\text { supercomplexity } \\
\text { Leadership for an } \\
\text { unknown future } \\
\text { Leadership as resilience } \\
\text { in action } \\
\text { Wicked problems } \\
\text { Presented in novella } \\
\text { format (narrated } \\
\text { identities) }\end{array}$ \\
\hline
\end{tabular}

Figure 2. Overview of the paradigm shift enacted in my professional practice

The research project is rooted in narrative, as an outcome (the artefact) and analytic practice and process (the collection, collation and re-presentation of the data as stories). A focus on the creation of personae and vignettes sits firmly in my academic discipline of languages and applied linguistics while honouring my whakapapa of Gaelic storytelling - my paternal grandfather was a seannachi. ${ }^{3}$ I remain, in this sense, true to my ethnic heritage and enact it as a cultural practice within the doctoral project. I am speaking as the imigrée blanche (Braidotti, 20 I4), in transit with (my) mother tongue, deploying (my) first language in a variety of genres as a monolingual polyglot, and (operating) in multiple languages in multiple contexts (nomadic polyglot), as identified during the earlier stages of the programme in the Review of Learning (McGirr, 2019a).

\section{Articulation and movement}

The shift regarding my own role has logically informed my research. The move from a previous management role to a current leadership position has informed a change in paradigm, methodology and methods for the project.

I have moved from seeking to understand the essence of a specific phenomenon through a co-constructed dialogue to an exploration beyond the unitary model of qualitative study. There are commonalities in both proposals - a wish to document and recount lived experience of educators within a particular locus, the intention to conduct analysis by and in writing, and the presentation of hybrid narrative vignettes as a part of the final project thesis. 
The lens though which I view my professional self, space and place informs the recalibration of the work. I am keen to investigate the domain of leadership in practice as viewed through a feminist lens, drawing on my condition of female leadership in the VET sector. The notion of our unprecedented national context brings added complexity, and places greater value on effective leadership at a time of transition and transformation, as the government of Aotearoa-New Zealand seeks to create a unified, world-class vocational education entity, the New Zealand Institute for Skills and Technology (NZIST) (Ministry of Education, 2020).

\section{Reflections}

In the era of the so-called "new normal," volatility, unpredictability and continuous recalibration are normal. In hindsight, and knowing that the professional journey is not linear, I might have couched the initial doctoral study differently; I could have given more consideration to how leaving one employer for another may have played out in the banal terrain of termination discussions. Searching through the original proposal, I noted a confident comment regarding mitigation of a risk relating to geopolitical instability and its impact on tenure:

The choice of the study has been based on the ... consideration (of) access to the study participants and materials - this is contingent upon my continuance in post at MENA $U$, where the research study will take place. In order to conduct the primary research, I need to be in situ to undertake the interviews, focus groups and observations. Equally, physical presence on site will enable me to access the secondary (documentation) data sourced from the MENA U.This this will be feasible as I am currently contracted until August 20 I8. (McGirr, 20 I9a, p. 16).

I have learned valuable lessons about agency and power (Billett, 20 I I) and the perils of geopolitical factors and professional stability:

I would have done well to consider more the professional curveball of opportunity - a once-in-a-lifetime chance which might eventuate (or not) - and the effect the choice to move roles far from the original place of investigation would have.

If, as I have claimed, I am "a multicultural individual, a migrant turned nomad" (Braidotti, 20 I I, p. I2), an imigrée blanche (Braidotti, 20 I4), my identity is bound up in continuous (re)assimilation - always re-thinking entry into the academic game.

Taleb (20 I2) might suggest that I have merely worked with the volatility (the sudden change in approval), absorbed the stressor (the effective end of my right to continue with my doctoral research) and made meaning from the disorder (geographical, professional and practice shifts). I may attest to the deployment of intrinsic pedagogic approaches to manage these multiple "ever changing futures" (Trede \& McEwen, 2013) which I have lived and experienced as part of my experiential learning through work.

\section{CONCLUSION (or, on becoming Hydra)}

In the realm of critical reflection, this bumpy moment roadblock has served me well.Viewing the experience through the lens of Antifragility (Taleb, 2012), I have gained from the disorder of the consequences of my professional choices and that which I cannot control, landing in a place of positivity. In some small way, I became Hydra - I grew another doctoral head when the one I had was effectively excised by the disruption of the irruptive communication which now seems a million miles and years away. 
As deputy chief executive of Otago Polytechnic, Oonagh McGirr is the strategic lead for academic development. She has led a diverse range of portfolios including learning and teaching; quality; learning and teaching development; global engagement; work-based learning; education for sustainability; and research and postgraduate. Oonagh has worked in international higher education for three decades in both the public and private sectors. She has taught on foundation, undergraduate and postgraduate programmes in modern foreign languages, cultural studies, linguistics, teacher education and research in multidisciplinary settings at new and legacy Higher Education Institutes in Europe and the Middle East. Her research interests are academic leadership, teacher identity in practice in higher education, and the development of sustainable CPD frameworks for HE practitioners. Oonagh is a Fellow of the Royal Society of the Arts. In addition, she is currently enrolled in Capable NZ's Doctorate in Professional Practice.

\section{Contact details: Oonagh.McGirn@op.ac.nz}

Baumeister, R. F. (1999). The nature and structure of the self: An overview. In R. F. Baumeister (Ed.), The self in social psychology (pp. I-24). Philadelphia, PA: Psychology Press.

Becher,T., \& Trowler, P. (200I). Academic tribes and territories: Intellectual enquiry and the culture of disciplines. Buckingham, UK: Society for Research into Higher Education.

Billett, S. (20I I). Subjectivity, self and personal agency in learning through and for work. In L. C. M. Malloch, The Sage handbook of workplace learning (pp. 60-72). London, UK: Sage.

Braidotti, R. (201 I). Nomadic subjects: Embodiment and sexual difference in contemporary feminist theory. New York, NY: Columbia University Press.

Braidotti, R. (2014, February). "Françoise Collin, l'immigrée blanche." Retrieved from https://rosibraidotti.com/publications/francoisecollin-limmigree-blanche/

Braidotti, R. (2014, Spring). Thinking with an accent: Françoise Collin, Les cahiers du grif, and French feminism. Signs: Journal of Women in Culture and Society, 39(3), 597-626.

Chickering, A. W., \& Gamson, Z. F. (1987). Seven principles for good practice in undergraduate education. The Wingspread Journal, $9(2) \mathrm{I}-\mathrm{IO}$.

Chickering, A., \& Reisser, L. (1993). Education and identity. San Francisco, CA: Jossey-Bass.

Ellis, C. (2004). The Ethnographic l:A methodological novel about autoethnography. Walnut Creek, CA:Altamira Press.

Ellis, C., Adam, T. E., \& Bochner, A. P. (20 I0). Autoethnography: An overview. Forum Qualitative Sozialforschung / Forum: Qualitative Social Research, $12(1$ ), Art. 10. Retrieved from https://www.qualitative-research.net/index.php/fqs/article/view/I589/3095

Head, B.W. (20 I5). Wicked problems: Implications for public policy and management. Administration \& Society, 47(6), 71 I-739.

Higher Education Academy. (20 I I). Professional standards framework. York, UK: Author.

Lester, S. (2004). Conceptualizing the practitioner doctorate. Studies in Higher Education, 29(6), 757-770. https:// doi: I 0. I080/0307507042000287249

McGirr, O. (2019a). A life in education revisited - Review of learning for the Doctorate in Professional Practice. Unpublished manuscript, Otago Polyechnic, Dunedin, NZ.

McGirr, O. (2019b, December). On second chances and epistemological shifts. Abstract submitted for the Second Otago Polyechnic Professional Practitioner Symposium, Dunedin, Otago-Otepoti, Aotearoa-New Zealand.

Ministry of Education (2020, August). Education (Vocational Education and Training Reform) Amendment Act 2020. Wellington, NZ: New Zealand Government.

Rieder, M. (20 8). Irish traveller language: An ethnographic and folk-linguistic exploration. Limerick, Ireland: Palgrave McMillan.

Romano, M. (2006). "Bumpy moments" in teaching: Reflections from practicing teachers. Teaching and Teacher Education, 22(8), 973-985.

Shepherd, S. (2017, April 20). Why are there so few female leaders in higher education: A case of structure or agency? Managment in Education, 31 (2), 82-87. 
Taleb, N. (2007). Black Swan. New York, NY: Random House Publishing.

Taleb, N. N. (20I2). Antifragile:Things that gain from disorder. New York, NY: Random House.

Trede, F., \& McEwen, C. (20I3). Educating the deliberate professional (Occasional Paper 9). Sydney, Australia: The Education for Practice Institute, Charles Sturt University.

Tripp, D. (1993, 2012). Critical incidents in teaching: Developing professional judgment. New York, NY: Routledge.

van Manen, M. (1997). Researching lived experience: Human science for an action sensitive pedagogy. London, Ontario:The Althouse Press.

van Manen, M. (20।4). Phenomenology of practice. Walnut Creek, CA: Left Coast Press.

I The New Zealand national Reform of Vocational Education, enacted on I April, 2020. This involved the creation of a single national lead body, The New Zealand Institute of Skills and Technology, and the creation of a network of 16 subsidiary institutes of technology and polytechnics as limited companies.

2 The amalgamation of two irruptive forces to create a single term - the national Reform of Vocational Education in New Zealand and Covid-19, the global pandemic which emerged in March 2020 and at the time of writing continues to undermine global health and economic stability.

3 Seannachí: Gaelic elder who presents stories through song and prose, exponent of an ancient practice prevalent in the coastal communities of Ireland. The practice is believed to be gifted as heritage in families, and usually passes from grandparent to grandchild. 